\title{
Atom Probe Tomography for Burnup and Fission Product Analysis for Nuclear Fuels
}

Mukesh Bachhav ${ }^{1}$, Lingfeng $\mathrm{He}^{1}$, Joshua Kane ${ }^{1}$, Xiang Liu ${ }^{1}$, Jian Gan ${ }^{1}$ and Francois Vurpiliot ${ }^{2}$

${ }^{1}$ Idaho National Laboratory, Idaho Falls, Idaho, United States, ${ }^{2}$ Normandie Université, Caen, HauteNormandie, France

The conventional and modern power reactors (such as PWR, BWR and AGR) use $\mathrm{UO}_{2}$ as a standard nuclear fuel since it provides necessary thermodynamic stability required in operating conditions [1-2]. However, the nuclear fuel during service is subjected to extreme condition of neutron irradiation, thermal, mechanical constraints which can influence its chemical, physico-chemical and microstructural properties of interest. Also, neutron irradiation leads to the formation of large number of fission products (FP) generated during burnup which can impact the chemical and mechanical properties of the fuel [3]. For instance, the release of gaseous fission products (xenon and krypton) can increase the pressure inside the fuel elements and contribute to the internal stresses on the cladding. Therefore, it is important to characterize the chemical and physical states of fission products in irradiated nuclear fuels which is often associated with amount of burnup and radial temperature gradient across fuel pin. The microstructure, composition, chemical and physical states of fission products, including metal and oxide precipitates and fission gas bubbles in both irradiated ceramic and metallic fuels have been characterized using Atom Probe Tomography (APT), Atomic-Resolution Scanning Transmission Electron Microscope (STEM) equipped with super-X energy dispersive X-ray spectroscopy (EDS) and electron energy loss spectroscopy (EELS) systems at Idaho National Laboratory (INL).

More often the irradiated microstructure of the fuel is heterogeneous, a reliable method to estimate the local burnup in nuclear fuels with sub-micron high spatial resolution becomes significant for evaluation of the local irradiated microstructure and its correlation to the general behavior of fuels [4]. Specimens were prepared from center and edge of $\mathrm{UO}_{2}$ fuel pin to determine the local burnup by quantification of U235 and U238 isotopes. Figure 1 shows 3D distribution of 5 metal precipitated (Mo-Tc-Ru-Rh-Pd) formed during irradiation of UO2 fuel and corresponding mass spectrum from the edge and center location of fuel. Analysis of specimen was carried out in laser mode as well as voltage mode which offered relatively poor yield to ensure correction to compositional biases introduced due to thermal tails in laser mode. APT analysis also allowed to investigate the fission products formation and their distribution for spent $\mathrm{UO}_{2}$ fuels which can be directly associated with the burnup levels of the fuel and temperature gradient. These results provided insight into fundamental understanding of fission products in ceramic and metallic nuclear fuels. 


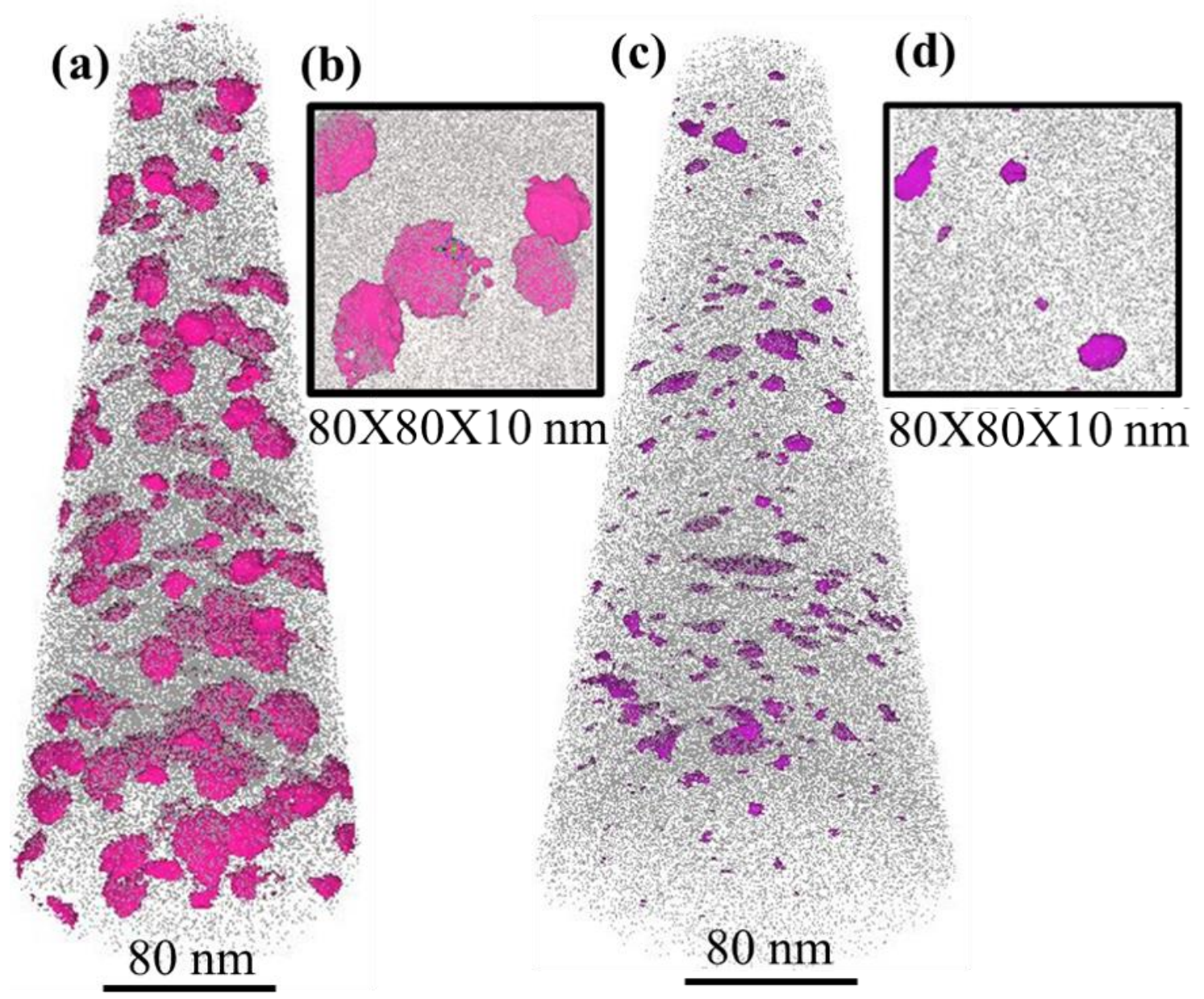

Figure 1. (a-b) 3D distribution of 5 metal precipitates of Mo-Tc-Ru-Rh-Pd (fission products) shown with iso-concentration surfaces formed in the edge location and (c-d) center location of irradiated UO2 fuel.
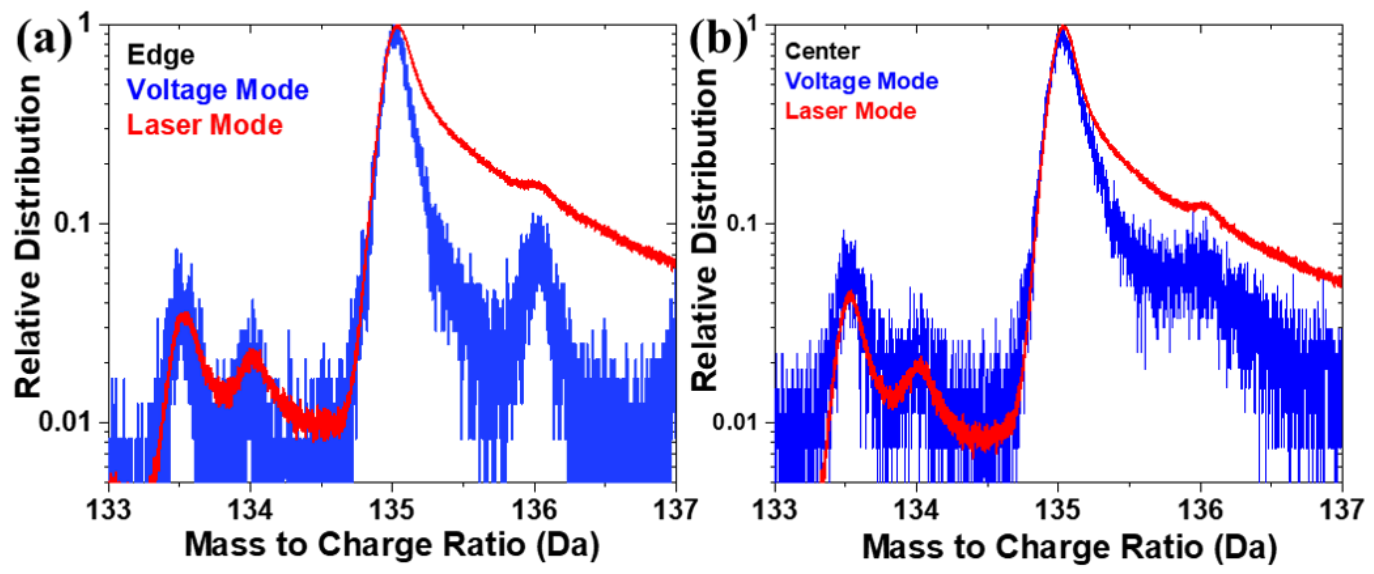

Figure 2. (a-b) Mass spectrum obtained using laser and voltage mode for 235UO22+, 236UO22+ and $238 \mathrm{UO} 22+$ from the edge and center location of irradiated UO2 fuel respectively. 


\section{.References}

[1] Une, K., K. Nogita, S. Kashibe, and M. Imamura. "Microstructural change and its influence on fission gas release in high burnup UO2 fuel." Journal of nuclear materials 188 (1992): 65-72.

[2] Sasahara, A., and T. Matsumura. "Post-irradiation examinations focused on fuel integrity of spent BWR-MOX and PWR-UO2 fuels stored for 20 years." Nuclear Engineering and Design 238, no. 5 (2008): 1250-1259.

[3] Rest, J., M. W. D. Cooper, J. Spino, J. A. Turnbull, P. Van Uffelen, and C. T. Walker. "Fission gas release from UO2 nuclear fuel: A review." Journal of Nuclear Materials 513 (2019): 310-345.

[4] Bachhav, Mukesh, Jian Gan, Dennis Keiser, Jeffrey Giglio, Daniel Jädernäs, Ann Leenaers, and Sven Van den Berghe. "A novel approach to determine the local burnup in irradiated fuels using Atom Probe Tomography (APT)." Journal of Nuclear Materials 528 (2020): 151853. 